\title{
Effects of the Treg/Th17 cell balance and their associated cytokines in patients with hepatitis $B$ infection
}

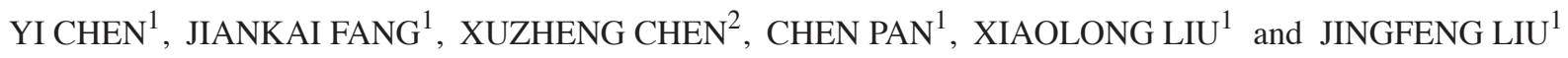 \\ ${ }^{1}$ The Liver Center of Fujian Province, Mengchao Hepatobiliary Hospital of Fujian Medical University, \\ Fuzhou, Fuijan 350025; ${ }^{2}$ Academy of Integrative Medicine, Fujian University of Traditional Chinese Medicine, \\ Fuzhou, Fuijan 350108, P.R. China
}

Received May 16, 2014; Accepted November 18, 2014

DOI: $10.3892 / \mathrm{etm} .2014 .2104$

\begin{abstract}
The extent to which T-cell-mediated immunity is impaired in patients with hepatitis B virus (HBV) infection remains controversial. In addition, the role of $\mathrm{T}$ regulatory (Treg) and T helper 17 (Th17) cells and their associated cytokines in immunity is not clear. In the present study, peripheral blood samples were collected from 44 patients with chronic hepatitis B virus, 14 asymptomatic hepatitis B carriers, 19 patients with liver cirrhosis and 20 healthy individuals. Flow cytometry was used to detect the percentages of $\mathrm{T}$ cell subsets in the samples, including $\mathrm{CD}^{+}, \mathrm{CD}^{+}$and $\mathrm{CD}^{+} \mathrm{T}$ cells, Treg cells and Th17 cells. A cytometric bead array was conducted to detect the levels of interleukin (IL)-17, $-6,-10$ and -21 , and transforming growth factor (TGF)- $\beta$. The data revealed that Treg cell levels decreased, while Th17 cell levels increased in the peripheral blood of HBV patients. As the extent of inflammation and fibrosis in the hepatic tissue increased, the frequency of Treg and Th17 cells in the peripheral blood did not significantly differ. In addition, the levels of Th17 cells were found to positively correlate with TGF- $\beta$ and IL-21 levels. Therefore, analyzing the balance between Treg/Th17 cells and their associated cytokines may be a useful indicator in the diagnosis of HBV.
\end{abstract}

Correspondence to: Dr Xiaolong Liu or Dr Jingfeng Liu, The Liver Center of Fujian Province, Mengchao Hepatobiliary Hospital of Fujian Medical University, 312 Xihong Road, Fuzhou, Fujian 350025, P.R. China

E-mail: xiaoloong.liu@gmail.com

E-mail: drjingfeng@126.com

Abbreviations: LC, liver cirrhosis; HBV, hepatitis B virus; $\mathrm{CHB}$, chronic hepatitis B virus; ASC, asymptomatic carrier; NC, normal control; CBA, cytometric bead array; IL, interleukin; Treg, $\mathrm{T}$ regulatory; Th17, $\mathrm{T}$ helper 17 ; TGF- $\beta$, transforming growth factor- $\beta$; FACS, fluorescence-activated cell sorting; ACLF, acute-on-chronic liver failure

Key words: hepatitis B virus, $\mathrm{T}$ regulatory cell, $\mathrm{T}$ helper 17 cell, cytokine, interleukin

\section{Introduction}

Hepatitis B is a serious health risk. The hepatitis B virus (HBV) is a non-cytopathogenic hepadnavirus. The prognosis of an HBV infection is closely associated with the condition of the immune system. The majority of liver damage in HBV patients is caused by the removal of infection from liver cells by the immune system, which produces a variety of inflammatory cytokines by non-specific $\mathrm{T}$ cells (1). Immunologically, the key to treating HBV is to restore an effective $\mathrm{T}$ cell response in patients with chronic hepatitis B (CHB) infection. Previous studies have confirmed that the immune system can remove cccDNA by a non-cellular destructive mechanism (1-3). Thus, the immunological treatment of $\mathrm{HBV}$ is attracting widespread attention and is expected to become an important approach for the treatment of CHB. However, there is currently no specific immune therapy that produces a good curative effect on HBV.

The functions of $\mathrm{T}$ regulatory (Treg) cells and $\mathrm{T}$ helper 17 (Th17) cells in the underlying mechanism of CHB are being increasingly investigated. However, the changes in Treg and Thl7 cell levels in the peripheral blood and the subsequent impact on the development of HBV infection have not yet been characterized, which is due primarily to the different definitions of target cells and detection methods. In addition, the interactions between associated cytokines remain unclear. Previous studies have demonstrated that chronic HBV infection increases the number of Treg cells in the peripheral blood and the liver, inhibiting HBV-specific T cell proliferation in vitro (4-6). Removing the Treg cells has been observed to enhance the specific immune reaction. Thus, the activity of $\mathrm{CD} 4{ }^{+} \mathrm{CD} 25^{+}$Treg cells in chronic HBV infection is one of the reasons for the persistent nature of HBV infection (7-9). Decreasing the number of Treg cells or inhibiting their activity has been hypothesized to overcome immune tolerance, strengthening the rate of virus removal. Previous studies on Treg cells in tumor-immunotherapy have demonstrated a significant effect on tumors through the use of mouse models (10-12). Prior to vaccine therapy, removing the Treg cells from kidney cancer patients has been shown to result in a 100-fold increase in specific T cell levels (13); however, research into the treatment of $\mathrm{HBV}$ infection using this method has not yet been reported. The aim of the present study was to 
Table I. Patient characteristics.

\begin{tabular}{|c|c|c|c|c|}
\hline Patient characteristics & $\mathrm{CHB}(\mathrm{n}=44)$ & $\operatorname{ASC}(n=14)$ & $\mathrm{LC}(\mathrm{n}=19)$ & Normal $(n=20)$ \\
\hline Gender (male:female), $\mathrm{n}$ & $33: 11$ & $10: 3$ & $14: 5$ & 10:10 \\
\hline Median age, years (range) & $35(9-63)$ & $33(15-59)$ & $67(29-76)$ & $32(23-45)$ \\
\hline Grade (low:middle:heavy), n & $20: 15: 9$ & & & \\
\hline Other diseases (HDV), $\mathrm{n}$ & 2 & & & \\
\hline
\end{tabular}

Direct comparison of the clinical features of patients in the CHB, ASC, LC and normal groups. CHB, chronic hepatitis B; ASC, asymptomatic carrier; LC, liver cirrhosis; HDV, hepatitis D virus.

investigate the changes in the levels of Treg and Th17 cells and their associated cytokines following HBV infection.

\section{Materials and methods}

Blood samples and instruments. Heparinized peripheral blood samples were obtained from patients with HBV in accordance with the CHB prevention guidelines (1). The use of human samples in the present study was approved by the Institution Review Board of Mengchao Hepatobilliary Hospital of Fujian Medical University (Fizhou, China). Written informed consent was received from all participants. Clinical diagnosis of patients with HBV met the diagnostic criteria for chronic hepatatis of the Chinese Association for the study of Liver Diseases (WS299-2008). There were four blood sample groups: Liver cirrhosis (LC), CHB, asymptomatic carrier (ASC) and normal control (NC). Clinical characteristics were recorded (Table I) and analyzed using the paired Student's t test .

A FASCabilur flow cytometer (BD Biosciences, Franklin Lakes, NJ, USA) was used to measure the levels of Treg cells, Th17 cells and cytokines, including TGF- $\beta$, IL-17, -6, -10 and -21 , in the peripheral blood. In 83/90 patients with $\mathrm{HBV}$, cytokines were detected using a cytometric bead array (CBA). The remaining seven patients were not included as their serum samples were not collected. In addition, peripheral blood samples were obtained from 20 healthy controls for measurement of cytokines, and Treg/Th17 levels.

$T$ cell subsets. Fluorescence-activated cell sorting (FACS) analysis was conducted to measure the levels of $\mathrm{CD}^{+}, \mathrm{CD}^{+}$and $\mathrm{CD}^{+} \mathrm{T}$ cells in the peripheral blood of the four groups, and subsequently the $\mathrm{CD}^{+} / \mathrm{CD}^{+} \mathrm{T}$ cell ratio. Measurements were collected using Multiset software (BD Biosciences), which is a four-color lymphocyte automated analysis.

Treg levels. FACS analysis was conducted to measure the Treg cell frequency in the peripheral blood. The levels were measured using CD4 PerCP-CY5.5, CD25 PE and CD127 Alexa Fluor 647 antibodies $(0.05 \mathrm{mg} / \mathrm{ml}$ BD Biosciences). The cells were incubated with the antibodies for $15 \mathrm{~min}$ prior to abstersion. $\mathrm{CD} 4^{+} \mathrm{CD} 25^{-\mathrm{CD}} 127^{+}$cells were used as surface markers to indicate a positive cell group.

Th17 levels. Th17 cell levels were measured using IL-17 PE, mouse IgG1 PE, CD8 FITC and CD3 PerCP antibodies (BD Biosciences). Blood samples were stimulated using phorbol 12-myristate 13 -acetate $(50 \mathrm{ng} / \mathrm{ml}$; Sigma-Aldrich, St. Louis, MO, USA) and ionomycin ( $1 \mu \mathrm{g} / \mathrm{ml}$; Sigma-Aldrich), and incubated for $5 \mathrm{~h}$ at $37^{\circ} \mathrm{C}$. The CD8 FITC and CD3 PerCP antibodies were used as surface markers for staining. Fixation and permeabilization of the cells was performed using an intracellular staining kit $(0.05 \mathrm{mg} / \mathrm{ml}$; BD Biosciences), according to manufacturer's instructions. IL-17 PE was an intracellular antibody and mouse IgG1 PE was used as the negative control.

Cytokine levels. Multi-target streaming protein quantitative technology (BD-Pharmigen Cytometric Bead Array; BD Biosciences) was used to detect the cytokine levels in the peripheral blood, following the manufacturer's instructions.

Statistical analysis. All statistical analyses were performed using SPSS version 19.0 (SPSS Inc., Chicago, IL, USA). Quantitative data between two groups were compared by two-tailed unpaired student's t test, and the data were expressed as the mean \pm standard deviation. $\mathrm{P}<0.05$ was considered to indicate a statistically significant difference.

\section{Results}

Percentages of $T$ cell subsets in the peripheral blood of the four groups show no significant differences. Percentages of $\mathrm{T}$ cells in the peripheral blood can be used as an indication of the functional status of the immune system. To analyze the functional status of the immune system in the four groups, the levels of $\mathrm{CD}^{+}, \mathrm{CD}^{+}$, and $\mathrm{CD}^{+} \mathrm{T}$ cells, and the $\mathrm{CD} 4^{+} / \mathrm{CD}^{+}$ $\mathrm{T}$ cell ratio, were analyzed using flow cytometry (Fig. 1). The percentages of $\mathrm{CD}^{+} \mathrm{T}$ cells in the $\mathrm{LC}, \mathrm{CHB}, \mathrm{ASC}$ and NC groups were $76.19 \pm 15.40,70.80 \pm 7.69,74.00 \pm 7.81$ and $74.50 \pm 6.47 \%$, respectively (Table II). The percentages of CD4 ${ }^{+}$ T cells in the LC, CHB, ASC and NC groups were 34.48 \pm 11.03 , $33.64 \pm 8.76,29.67 \pm 25.15$ and $28.50 \pm 8.64 \%$, respectively. Furthermore, the percentages of $\mathrm{CD}^{+} \mathrm{T}$ cells in the $\mathrm{LC}$, CHB, ASC and NC groups were 26.00 $\pm 12.28,29.07 \pm 8.87$, $39.67 \pm 15.95$ and $40.17 \pm 9.70 \%$, respectively. No statistically significant differences were observed in the percentages of $\mathrm{T}$ cell subsets $\left(\mathrm{CD}^{+}, \mathrm{CD}^{+}\right.$and $\mathrm{CD}^{+} \mathrm{T}$ cells) among the four groups $(\mathrm{P}>0.05)$. In addition, the ratios of $\mathrm{CD}^{+} / \mathrm{CD}^{+}$ cells in the LC, CHB, ASC and NC groups were 1.58 \pm 0.70 , $1.40 \pm 1.01,1.10 \pm 1.33$ and $0.78 \pm 0.38$, respectively. There were no statistically significant differences among the four groups with regard to the $\mathrm{CD}^{+} / \mathrm{CD}^{+}$ratios $(\mathrm{P}>0.05)$. 
A

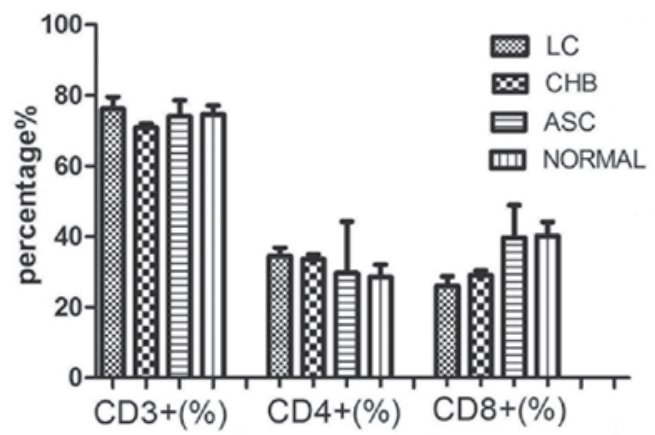

B

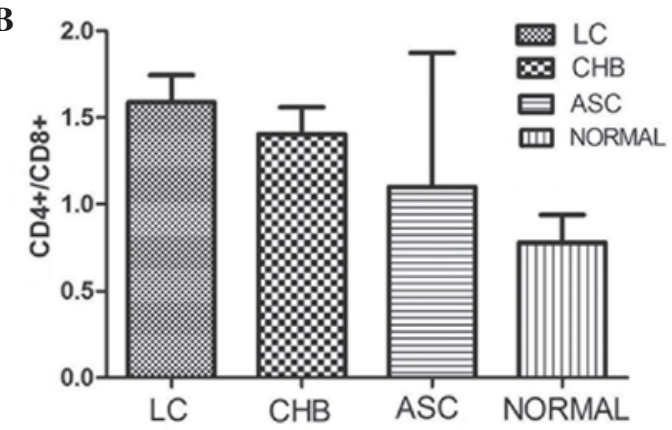

Figure 1. (A) Percentages of $\mathrm{CD}^{+}, \mathrm{CD} 4^{+}$and $\mathrm{CD} 8^{+} \mathrm{T}$ cells and the (B) ratio of $\mathrm{CD} 4^{+} / \mathrm{CD} 8^{+} \mathrm{T}$ cells in the peripheral blood of the four groups (P>0.05). $\mathrm{LC}$, liver cirrhosis; $\mathrm{CHB}$, chronic hepatitis $\mathrm{B}$; ASC, asymptomatic carrier; $\mathrm{NC}$, normal control.

A

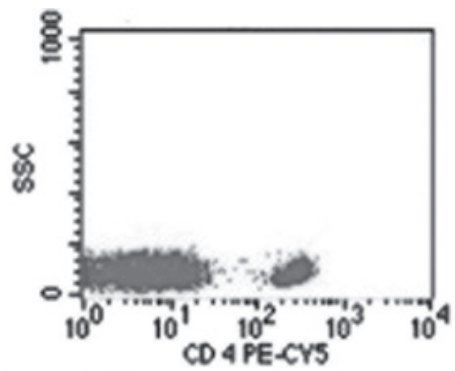

C

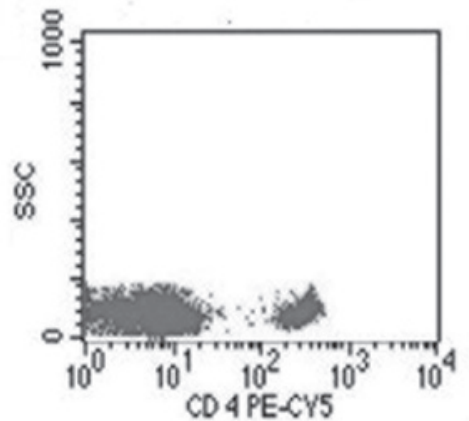

$\mathbf{E}$

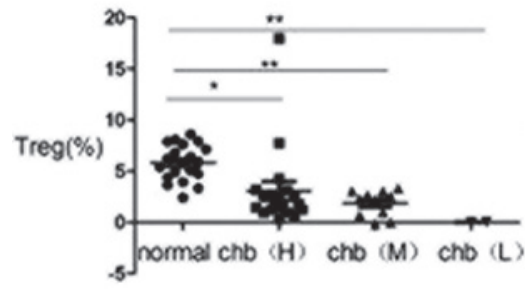

B

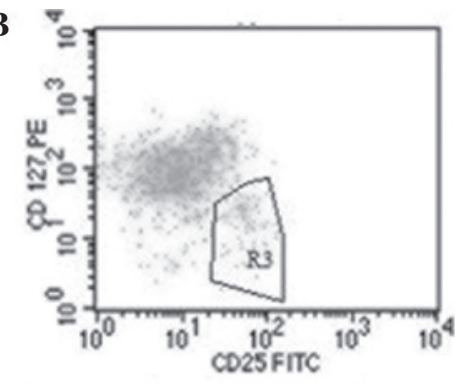

D

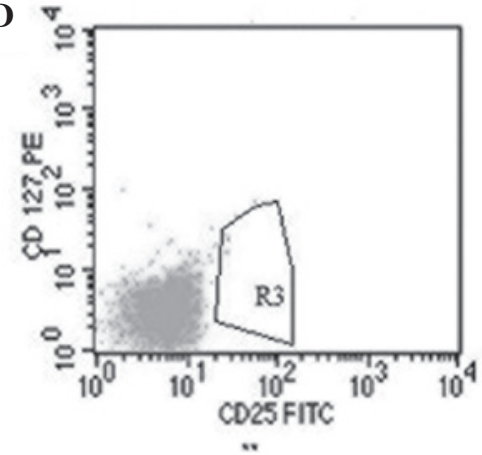

$*$

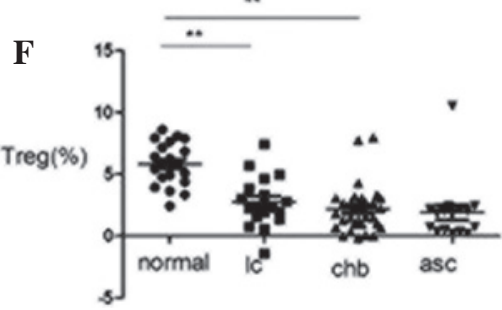

Figure 2. Flow cytometric analysis of the Treg cell levels. The percentages in each image represent the levels of the analyzed cell subsets, (A and B) $\mathrm{CD}^{+} \mathrm{CD} 25^{+} \mathrm{CD} 127$ (low) and (C and D) negative control (immunoglobulin $\mathrm{G}$ antibody). Percentages of Treg cells (E) in the heavy, middle and low CHB groups and (F) in the CHB, LC and ASC groups. " $\mathrm{P}<0.05$ and ${ }^{* *} \mathrm{P}<0.01$. Treg, T regulatory; CHB, chronic hepatitis B; LC, liver cirrhosis; ASC, asymptomatic carrier.

Percentages of Treg and Th17 cells are elevated in the LC, $\mathrm{CHB}$ and ASC groups. Levels of $\mathrm{CD} 4{ }^{+} \mathrm{CD} 25^{+} \mathrm{CD} 127^{-}$Treg cells and $\mathrm{CD} 4^{+} \mathrm{IL}-17^{+} \mathrm{Th} 17$ cells were analyzed and the representative flow cytometry results are shown in Figs. 2 and 3. Furthermore, the percentages of Treg and Th17 cells in patients with different stages of CHB (Figs. 2E and 3E) were analyzed. The percentages of $\mathrm{CD} 4^{+} \mathrm{CD} 25^{+} \mathrm{CD} 127^{-}$Treg cells in the NC group and heavy, middle and light $\mathrm{CHB}$ groups were $5.82 \pm 1.76,3.08 \pm 3.96,1.89 \pm 1.26$ and $0.025 \pm 0.04 \%$, respectively. The percentages of Th17 cells in the NC group and heavy, middle and light CHB groups were $0.44 \pm 0.24$,
$2.38 \pm 4.10,2.36 \pm 3.85$ and $1.82 \pm 1.69$, respectively (Table III). There were no statistically significant differences observed among the heavy, middle and light CHB groups $(\mathrm{P}>0.05)$.

Percentages of Treg and Th17 cells in the peripheral blood of the NC, LC, CHB and ASC groups were also analyzed by flow cytometry (Figs. $2 \mathrm{~F}$ and $3 \mathrm{~F}$ ). The percentages of Treg cells in the NC, LC, CHB and ASC groups were $5.83 \pm 1.76,2.74 \pm 2.06,2.17 \pm 1.88$ and $1.90 \pm 2.45 \%$, respectively. Statistically significant differences were observed between the $\mathrm{NC}$ group and the other three groups $(\mathrm{P}<0.05$, $\mathrm{P}<0.01)$. The percentages of Th17 cells in the NC, LC, CHB 
Table II. Proportion of T lymphocytes in the four groups (\%).

\begin{tabular}{lcccc}
\hline Cell types & LC & CHB & ASC & Normal \\
\hline $\mathrm{CD}^{+}$T cell & $76.19 \pm 15.40$ & $70.80 \pm 7.69$ & $74.00 \pm 7.81$ & $74.50 \pm 6.47$ \\
$\mathrm{CD}^{+}$T cell & $34.48 \pm 11.03$ & $33.64 \pm 8.76$ & $29.67 \pm 25.15$ & $28.50 \pm 8.64$ \\
$\mathrm{CD}^{+}$T cell & $26.00 \pm 12.28$ & $29.07 \pm 8.87$ & $39.67 \pm 15.95$ & $40.17 \pm 9.70$ \\
$\mathrm{CD}^{+} / \mathrm{CD} 8^{+}$ratio & $1.58 \pm 0.70$ & $1.40 \pm 1.01$ & $1.10 \pm 1.33$ & $0.78 \pm 0.38$ \\
$\mathrm{CD} 4^{+} \mathrm{CD} 25^{+}$Treg & $2.74 \pm 2.06^{\mathrm{a}}$ & $2.17 \pm 1.88^{\mathrm{a}}$ & $1.90 \pm 2.45^{\mathrm{a}}$ & $5.83 \pm 1.76^{\mathrm{a}}$ \\
$\mathrm{CD} 4^{+} \mathrm{IL} 17^{+}$Th17 & $3.19 \pm 2.94^{\mathrm{a}}$ & $2.72 \pm 4.79^{\mathrm{a}}$ & $1.63 \pm 1.53^{\mathrm{a}}$ & $0.44 \pm 0.24^{\mathrm{a}}$ \\
\hline
\end{tabular}

Quantitative results from flow cytometric analysis. ${ }^{\mathrm{P}}<0.01$, vs. normal group. LC, liver cirrhosis; CHB, chronic hepatitis B; ASC, asymptomatic hepatitis B carrier; IL-17, interleukin-17; Treg, T regulatory; Th17, T helper 17.

A

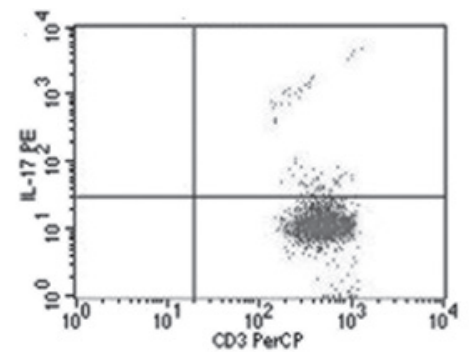

C

$\mathbf{E}$
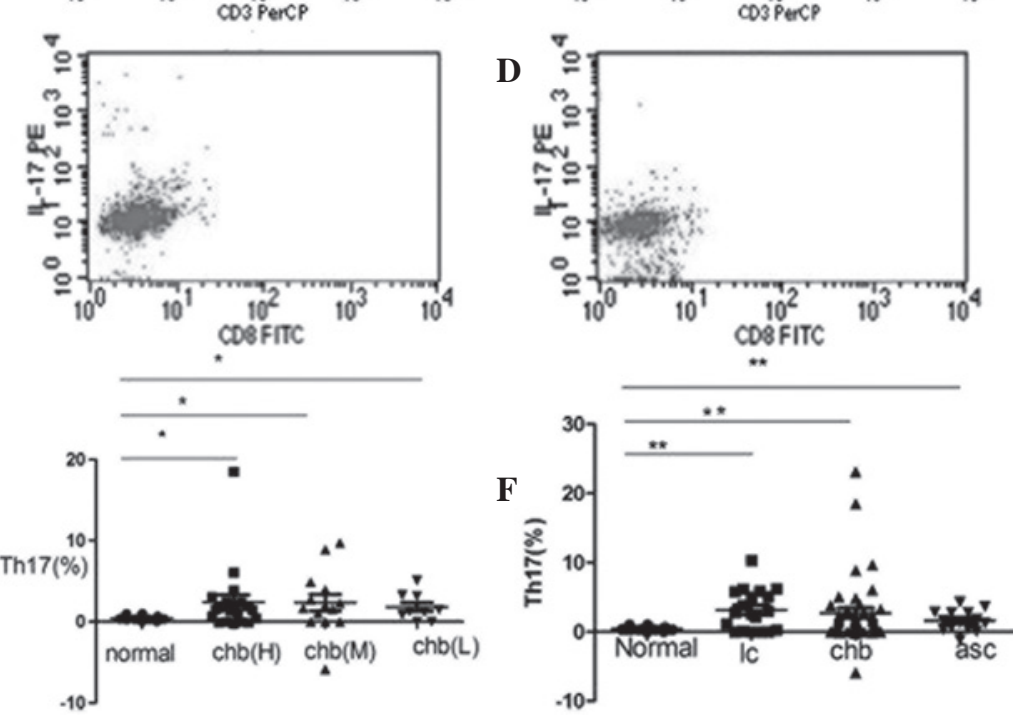

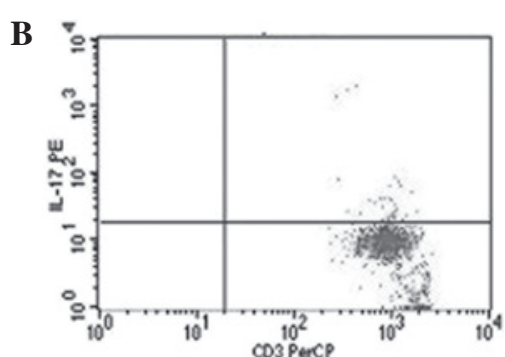

Figure 3. Flow cytometric analysis of IL-17 $\mathrm{Th} 17$ cells. The percentages in each figure represent the levels of the analyzed cell subsets. (A and C) Blood samples were stimulated with phorbol 12-myristate 13-acetate and ionomycin. (B and D) Blood samples were not stimulated. (E) Percentages of Th17 cells in the heavy, middle and low CHB groups and the normal control. (F) Percentages of Th17 cells in the normal, LC, CHB and ASC groups. ${ }^{*} \mathrm{P}<0.05$ and ${ }^{* *} \mathrm{P}<0.01$. IL, interleukin; Th17, T helper 17; CHB, chronic hepatitis B; LC, liver cirrhosis; ASC, asymptomatic carrier.

and ASC groups were $0.44 \pm 0.24,3.19 \pm 2.94,2.72 \pm 4.79$ and $1.63 \pm 1.53 \%$, respectively (Table II). Similarly, statistically significant differences were identified between the NC group and the other three groups $(\mathrm{P}<0.01)$.

Cytokine levels in the peripheral blood of the NC group are significantly different compared with the other groups. CBAs were performed to measure the expression levels of the cytokines, TGF- $\beta$, IL-21, $-6,-10$ and -17 , in the peripheral blood of the four groups (Fig. 4). Cytokine levels in the NC group differed significantly when compared with the other three groups. In addition, Th17 cell levels were shown to positively correlate with the TGF- $\beta$ and IL-21 levels. 
Table III. Proportions of T lymphocytes in the three CHB groups (\%).

\begin{tabular}{lcccc}
\hline Cell types & Heavy group & Middle group & Mild group & Normal group \\
\hline $\mathrm{CD} 4^{+} \mathrm{CD} 25^{+}$Treg & $3.08 \pm 3.96^{\mathrm{a}}$ & $1.89 \pm 1.26^{\mathrm{b}}$ & $0.025 \pm 0.035^{\mathrm{b}}$ & $5.82 \pm 1.76$ \\
$\mathrm{CD} 4{ }^{+} \mathrm{IL} 17^{+}$Th17 & $2.38 \pm 4.10^{\mathrm{b}}$ & $2.36 \pm 3.85^{\mathrm{b}}$ & $1.82 \pm 1.69^{\mathrm{b}}$ & $0.44 \pm 0.24$ \\
\hline
\end{tabular}

Quantitative results from flow cytometric analysis. ${ }^{\mathrm{a}} \mathrm{P}<0.05$ and ${ }^{\mathrm{b}} \mathrm{P}<0.01$, vs. normal group. CHB, chronic hepatitis $\mathrm{B}$; Treg, T regulatory; IL-17, interleukin-17; Th17, T helper 17.

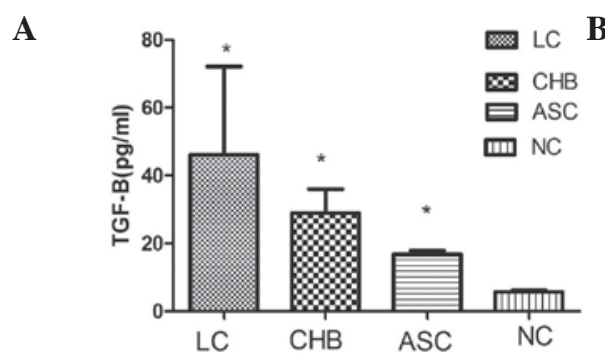

D
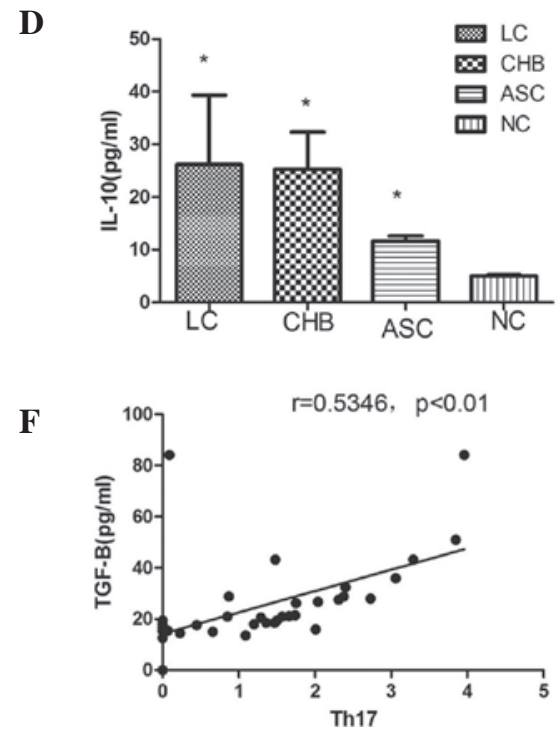
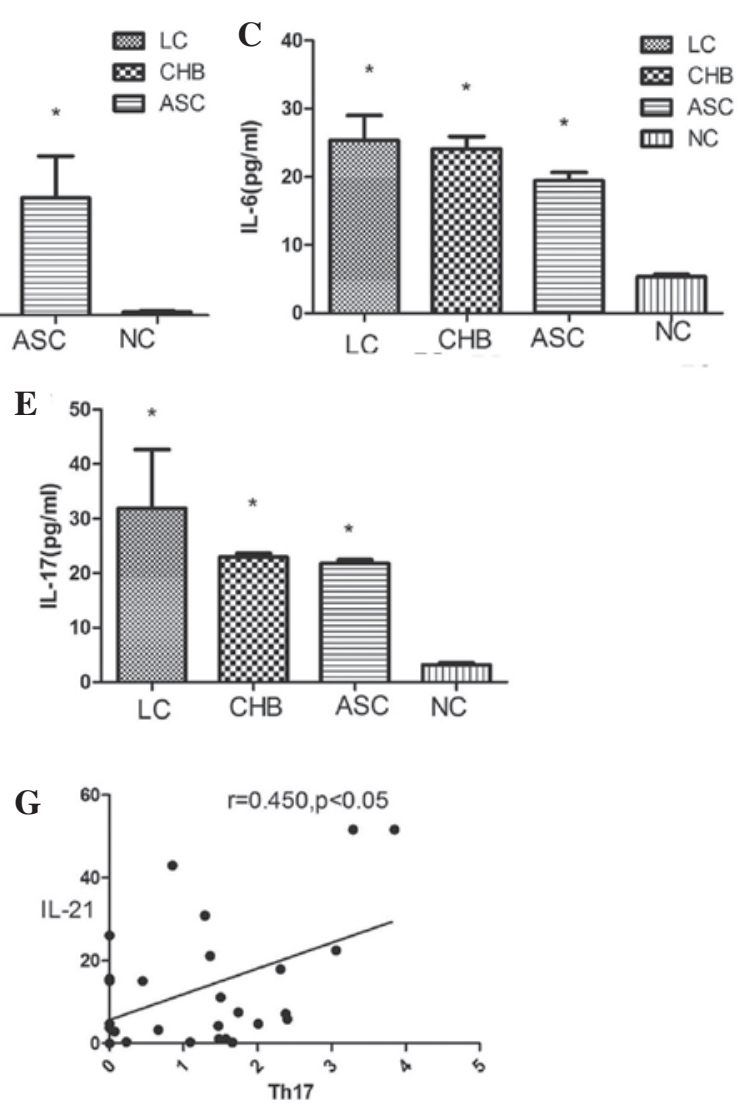

Figure 4. Expression levels of (A) TGF- $\beta$, (B) IL-21, (C) IL-6, (D) IL-10 and (E) IL-17 were measured using a cytometric bead assay. Correlation analyses were conducted between the levels of Th17 cells and (F) TGF- $\beta$ and (G) IL-21 levels in the CHB group, using Spearman's rank correlation. *P<0.05, vs the NC group. TGF- $\beta$, transforming growth factor- $\beta$; IL, interleukin; LC, liver cirrhosis; CHB, chronic hepatitis B; ASC, asymptomatic carrier; NC, normal control; Th17, T helper 17.

regulation of immune tolerance, but also play an important role in tumor immunity (17-20). Treg cells are a type of T lymphocyte with unique functions. Treg cells have been intensely studied due to their capacity to secrete IL-4, IL-10 and TGF- $\beta$. Th17 cells primarily secrete IL-17, and have numerous immune response-associated functions, including promoting the proliferation, maturation and chemotactic activity of neutrophils. In addition, Th17 cells may costimulate the activation of $\mathrm{T}$ cells and promote the maturation of dendritic cells (21).

In the present study, the T cell immunity of HBV patients was systematically investigated by analyzing the balance between Treg/Th17 cells and their associated cytokines. Peripheral blood samples were collected from four groups of individuals, including 44 patients with CHB, 14 ASCs, 19 patients with LC and 20 healthy controls. Samples were stained with different cell surface markers and intracellular makers prior to cytometric analysis. Multi-target streaming protein quantitative technology (CBA) was used to measure the cytokine levels, with the aim of providing further data for improving the treatment of $\mathrm{HBV}$.

Firstly, the total percentages of peripheral $\mathrm{CD}^{+}, \mathrm{CD}^{+}$and $\mathrm{CD} 8^{+} \mathrm{T}$ cells were measured. The results showed that there were no significant differences among the four groups, with regard to the total percentage of $\mathrm{CD}^{+}, \mathrm{CD}^{+}$and $\mathrm{CD}^{+}$, as compared with the NC group.

Secondly, the percentages of Treg and Th17 cells were measured. The results indicated that the levels of Treg cells in the peripheral blood of HBV patients decreased, however, the levels of Th17 cells increased. As the extent of inflammation and fibrosis in the hepatic tissue increased, the levels of Treg and Th17 cells in the peripheral blood samples exhibited heavy, middle and low distribution (Figs. 2E and 3E), in spite of there being no statistically significant differences in their 
distribution. The percentages of $\mathrm{CD} 4^{+} \mathrm{CD} 25^{+} \mathrm{CD} 127^{-}$Treg cells decreased significantly in the three CHB groups when compared with the NC group (Fig. 2F). Furthermore, the levels of $\mathrm{CD} 4^{+} \mathrm{IL}-17^{+} \mathrm{Th} 17$ cells in the three CHB groups increased significantly when compared with the NC group (Fig. 3F). The Treg cell results obtained in the present study differ from those obtained in previous studies $(13,22)$. Yu et al (23) found that levels of Treg cells were significantly increased in CHB patients $(n=70)$ and slightly increased in patients with HBV/LC $(n=28)$ when compared with normal controls $(n=20)$, whereas Th17 cell levels were markedly increased in the CHB and LC patients. In the study by Zhang et al (24), samples were collected from 14 patients at various stages of HBV-related acute-on-chronic liver failure (ACLF), and were compared with $30 \mathrm{CHB}$ patients and 18 healthy controls. The frequency of circulating Treg cells was significantly lower in the patients at the remission stage of ACLF when compared with those in the progression stage or in the CHB group. The increase in Th17 cells and concomitant decrease in Treg cells created an imbalance in the remission stage ACLF patients, which negatively correlated with disease progression. The results of the present study concur with these findings. However, future studies are required to further the understanding into the balance of Treg/Th17 cells in HBV patients.

Cytokines are important mediators of the immune response, including the immune response in the liver cells of HBV patients. In addition to being secreted by immune cells, cytokines exert feedback effects on the immune cells. During the course of HBV infection, the functions of a number of cytokines are ambiguous. For example, TGF- $\beta$ may stimulate $\mathrm{CD} 4^{+} \mathrm{T}$ cells to remove HBV by activating Treg cells. Alternatively, TGF- $\beta$, IL- 6 and IL-21 may promote the development of Th17 cells, which can enhance the local immune response in vivo (25-27). In the present study, the levels of TGF- $\beta$, IL-21, $-6,-10$ and -17 were detected using a CBA. Th17 cell levels were found to positively correlate with the levels of TGF- $\beta$ and IL-21, indicating that TGF- $\beta$ and IL-21 are key cytokines in the determination of cell differentiation (Fig. 4F and G). TGF- $\beta$ stimulation can result in the production of Treg or Th17 cells. As an autocrine regulatory factor, IL-21 induces differentiation and inhibits Th17 and Treg cell function. IL-21 function was revealed to be similar to that of IL-6. Therefore, TGF- $\beta$ and IL-21 may influence T cells that can be induced to differentiate into Thl7 cells. Increasing levels of these cytokines may reduce immune function and promote HBV development by affecting the Th17/Treg cell ratio. Thus, an imbalance in these cell types may be associated with the promotion and development of HBV infection.

\section{Acknowledgements}

This study was supported by a grant from the Fuzhou Science and Technology Plan Projects (no. 2011-S-69-1) and the Fujian Medical University Non-Affiliated Hospital Scientific Research and Development Plan Project (no. FZS13003Y).

\section{References}

1. Chinese Society of Hepatology and Chinese Society of Infectious Diseases, Chinese Medical Association: The guideline of prevention and treatment for chronic hepatitis B (2010 version). Zhonghua Gan Zang Bing Za Zhi 19: 13-24, 2011 (In Chinese).
2. Levrero M, Pollicino T, Petersen J, et al: Control of cccDNA function in hepatitis B virus infection. J Hepatol 51: 581-592, 2009.

3. Boni C, Fisicaro P, Valdatta C, et al: Characterization of hepatitis B virus (HBV)-specific T-cell dysfunction in chronic HBV infection. J Virol 81: 4215-4225, 2007.

4. Peng G, Li S, Wu W, et al: Circulating CD4+ CD25+ regulatory T cells correlate with chronic hepatitis B infection. Immunology 123: 1357-1365, 2008

5. Yang G, Liu A, Xie Q, et al: Association of CD4+CD25+Foxp3+ regulatory $\mathrm{T}$ cells with chronic activity and viral clearance in patients with hepatitis B. Int Immunol 19: 133-140, 2007.

6. Xu D, Fu J, Jin L, et al: Circulating and liver resident CD4+CD25+ regulatory $\mathrm{T}$ cells actively influence the antiviral immune response and disease progression in patients with hepatitis B. J Immunol 177: 739-747, 2006.

7. Kondo Y, Kobayashi K, Ueno Y, et al: Mechanism of T cell hyporesponsiveness to $\mathrm{HBcAg}$ is associated with regulatory $\mathrm{T}$ cells in chronic hepatitis B. World J Gastroenterol 12: 4310-4317, 2006.

8. Xu D, Fu J, Jin L, Zhang H, et al: Circulating and liver resident $\mathrm{CD} 4{ }^{+} \mathrm{CD} 25^{+}$regulatory $\mathrm{T}$ cells actively influence the antiviral immune response and disease progression in patients with hepatitis B. J Immunol 177: 739-747, 2006.

9. Stoop JN, van der Molen RG, Baan CC, et al: Regulatory T cells contribute to the impaired immune response in patients with chronic hepatitis B virus infection. Hepatology 41: 771-778, 2005.

10. Curiel TJ: Tregs and rethinking cancer immunotherapy. J Clin Invest 117: 1167-1174, 2007.

11. Ruter J, Barnett BG, Kryczek I, et al: Altering regulatory T cell function in cancer immunotherapy: a novel means to boost the efficacy of cancer vaccines. Frontier Biosci (Landmark Ed) 14: 1761-1770, 2009.

12. Juang CM, Hung CF, Yeh JY, et al: Regulatory T cells: potential target in anticancer immunotherapy. Taiwan J Obstet Gynecol 46: 215-221, 2007.

13. Greten TF, Manns MP and Korangy F: Immunotherapy of hepatocellular carcinoma: J Hepatol 45: 868-878, 2006.

14. Romagnani S: T cell subpopulations. Chem Immunol Allergy 100: $155-164,2014$.

15. Hall BM, Verma ND, Tran GT and Hodginkson SJ: Distinct regulatory CD4+T cell subsets; differences between naïve and antigen specific T regulatory cells. Curr Opin Immunol 23: 641-647, 2011.

16. Bettelli E, Carrier Y, Gao W, et al: Reciprocal developmental pathways for generation of pathogenic effector Thl7 and regulatory T cells. Nature 441: 235-238, 2006.

17. Zhang Y, Ma D, Zhang Y, et al: The imbalance of Th17/Treg in patients with uterine cervical cancer. Clin Clim Acta 412: 894-900, 2011.

18. Zhang B, Rong G, Wei H, et al: The prevalence of Th17 cells in patients with gastric cancer. Biochem Biophys Res Commun 374: 533-537, 2008 .

19. Miyahara Y, Odunsi K, Chen W, et al: Generation and regulation of human CD4+ IL-17-producing T cells in ovarian cancer. Proc Natl Acad Sci USA 105: 15505-15510, 2008.

20. Le Gouvello S, Bastuji-Garin S, Aloulou N, et al: High prevalence of Foxp3 and IL17 in MMR-proficient colorectal carcinomas. Gut 57: 772-779, 2008.

21. Alatrakchi $\mathrm{N}$ and Koziel M: Regulatory $\mathrm{T}$ cells and viral liver disease. J Viral Hepat 16: 223-229, 2009.

22. Chen Z, Ding J, Pang N, et al: The Th17/Treg balance and the expression of related cytokines in Uygur cervical cancer patients. Diagn Pathol 8: 61, 2013.

23. Yu XL, Guo R, Ming D, et al: Ratios of regulatory $\mathrm{T}$ cells/T-helper 17 cells and tranforming growth factor- $\beta 1 /$ interleukin- 17 to be associated with the development of hepatitis B virus-associated liver cirrhosis. J Gastronenterol Hepatol 29: 1065-1072, 2014.

24. Zhang GL, Xie DY, Lin BL, et al: Imbalance of interleukin-17-producing CD4 $\mathrm{T}$ cells/regulatory $\mathrm{T}$ cells axis occurs in remission stage of patients with hepatitis B virus-related acute-on-chronic liver failure. J Gastronenterol Hepatol 28: 513-521, 2013.

25. Li Y, Tang L and Hou J: Role of interleukin-21 in HBV infection: friend or foe? Cell Mol Immunol: Nov 3, 2014 (Epub ahead of print).

26. Arababadi MK, Bidaki MZ and Kennedy D: IL-17A in hepatitis B infection: friend or foe? Arch Virol 159: 1883-1888, 2014.

27. Kimura A and Kishimoto T: IL-6: regulator of Treg/Th17 balance. J Immunol 40: 1830-1835, 2010. 